\title{
PGC-1: The Energetic Regulator in Cardiac Metabolism
}

\author{
Wencheng $\mathrm{Di}^{1 \#}$, Jianjun $\mathrm{Lv}^{2,3 \#}$, Shuai Jiang ${ }^{4 \#,}$ \\ Chenxi Lu², Zhi Yang ${ }^{3}$, Zhiqiang $\mathrm{Ma}^{5}$, Wei $\mathrm{Hu}^{3}$, \\ Yang Yang ${ }^{2,3 *}$, and Biao $\mathrm{Xu}^{1 *}$ \\ ${ }^{1}$ Department of Cardiology, Affiliated Drum Tower \\ Hospital of Nanjing University Medical School, 321 \\ Zhongshan Road, Nanjing 210008, Jiangsu, China \\ ${ }^{2}$ Key Laboratory of Resource Biology and \\ Biotechnology in Western China, Ministry of \\ Education. Faculty of Life Sciences, Northwest \\ University, 229 Taibai North Road, Xi'an 710069, \\ China \\ ${ }^{3}$ Department of Biomedical Engineering, The Fourth \\ Military Medical University, 169 Changle West Road, \\ Xi'an 710032, China \\ ${ }^{4}$ Department of Aerospace Medicine, The Fourth \\ Military Medical University, 169 Changle West Road, \\ Xi'an 710032, China \\ ${ }^{5}$ Department of Thoracic Surgery, Tangdu Hospital, \\ The Fourth Military Medical University, 1 Xinsi Road, \\ Xi'an 710038, China
}

\#These authors contributed equally to this work.

*Correspondence: biaoxudrum@163.com; yang200214yy@163.com

DOI: https://dx.doi.org/10.21775/cimb.028.029

\footnotetext{
Abstract

The peroxisome proliferator-activated receptor $\mathrm{Y}$ (PPARy) coactivator-1s (PGC-1s) can induce the expression of several downstream genes that play pivotal roles in the regulation of mitochondrial biogenesis and metabolism in the heart. Moreover, PGC-1 signaling pathways have also been reported to play a critical role in cardioprotection. Given the significance of PGC-1 coactivators, we summarize the current literature on the molecular mechanisms and roles of PGC-1s in cardiac metabolism. Thus, in this review, we first introduce the basic knowledge regarding PGC-1 signaling pathways. We then discuss their roles in heart metabolism. Moreover, we describe several significant treatments that
}

target the PGC-1 signaling pathway. This review presents the significant roles of PGC-1s in cardiac metabolism and may contribute to the promotion of PGC-1 signaling pathway as a novel therapeutic target.

\section{Introduction}

The human heart consumes a huge amount of energy in form of adenosine triphosphate (ATP) every day. However, ATP reserves are merely sufficient for $10 \mathrm{~s}$ of cardiac function; thus, a constant supply of fuel is essential. Mitochondria serve as a power plant for cardiomyocytes and provide them with ATP to sustain contractile function. Free fatty acids (FAs) are the preferred energy substrate in healthy adult heart, supplying about $70 \%$ of total ATP, whereas other substrates such as glucose and lactate may provide additional fuel sources in diverse physiological and nutritional circumstances (Palomer et al., 2013). Short term energy supply is primarily modulated by the adenosine diphosphate (ADP)/ATP ratio and cytoplasmic free $\mathrm{Ca}^{2+}$ in the process of the oxidative phosphorylation (OXPHOS) and the tricarboxylic acid cycle (TAC), respectively. Long term transcriptional regulation is strongly linked to cardiac function: several upstream signals, such as $\mathrm{Ca}^{2+}$ as a mediator of excitation-contraction (E-C) coupling and 3 '-5'-cyclic adenosine monophosphate (cAMP) as a messenger of $\beta$-adrenergic pathway, activate the expression of peroxisome proliferator-activated receptor Y (PPARY) coactivator-1s (PGC-1s) (Tuomainen et al., 2017). PGC-1s are a family of

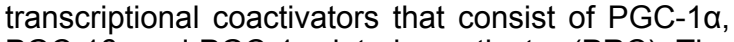
PGC-1 $\beta$, and PGC-1-related coactivator (PRC). The PGC-1 family can be regulated at both the transcriptional and post-translational levels, and they coactivate their specific partners, including estrogen-related receptors (ERRs), PPARs, and nuclear respiratory factors (NRFs). PGC-1 coactivators together with their specific partners regulate a myriad of transcription factors responsible for both energy metabolism and cardiac function, controlling mitochondrial biogenesis and 
function, mediating a shift in fuel usage, and modulating reactive oxygen species (ROS) homeostasis under physiological and pathological conditions. Moreover, cardiac PGC-1 coactivators appear to exert cardioprotective effects.

The focus of this review is to summarize the latest research progress on cardiac metabolism and protective effects of the PGC-1 coactivators against cardiac diseases. First, we introduce the biology and regulation of these coactivators as well as their coactivated targets. We then discuss some of their important functions in the cardiac system. Finally, we describe several significant cardiac disease treatments that target the PGC-1 signaling pathway, including medications, exercise training, and caloric restriction. Collectively, this review presents a comprehensive picture of the roles played by PGC-1 coactivators in cardiac metabolism, and it may contribute to the design of further experimental research and the promotion of PGC-1s as new therapeutic targets.

\section{An overview of PGC-1 signaling pathway}

\subsection{Biology of PGC-1}

PGC-1s are members of a family of transcriptional coactivators that consists of PGC- $1 \alpha, P G C-1 \beta$, and PRC, all of which play key roles in the regulation of mitochondrial biogenesis and metabolism. PGC-1 $\alpha$, the most studied member of the family, was originally identified in a yeast 2-hybrid screen as a coactivator of PPARy following cold exposure in brown adipose tissue, where it regulates adaptive thermogenesis and mitochondrial function (Puigserver et al., 1998). The other two PGC-1s were subsequently identified by their sequence homologies to PGC-1 $\alpha$. PGC-1 $\beta$, which is also known as PGC-1-related estrogen receptor coactivator (PERC), is capable of regulating many downstream targets controlled by PGC-1 $\alpha$ (Lin et al., 2002). PRC, the least known member of the family, largely due to the embryonic lethal phenotype of $P R C$ knockout mice, performs several functions in the regulation of mitochondrial biogenesis and inflammatory responses ( $\mathrm{He}$ et al., 2012; Gleyzer et al., 2013). PGC-1 $\alpha$ and PGC-1 $\beta$ are mainly expressed in tissues that demand high energy consumption, such as the heart, brain, brown adipose tissue, skeletal muscle, liver, and kidney, whereas PRC is expressed in all tissues. The PGC-1 family members have relatively short half-lives as a consequence of their rapid ubiquitination and proteasomal degradation (Trausch-Azar et al., 2015).

The amino acid sequence homology among the three members of the PGC-1 family is particularly high within both the $\mathrm{N}$ - and $\mathrm{C}$-terminal ends of the proteins, where a few conserved domains have been described. (Figure 1) The $\mathrm{N}$-terminal regions of PGC-1s contain a highly conserved activation domain that interacts with proteins with histone acetyltransferase (HAT) activity, including cAMP

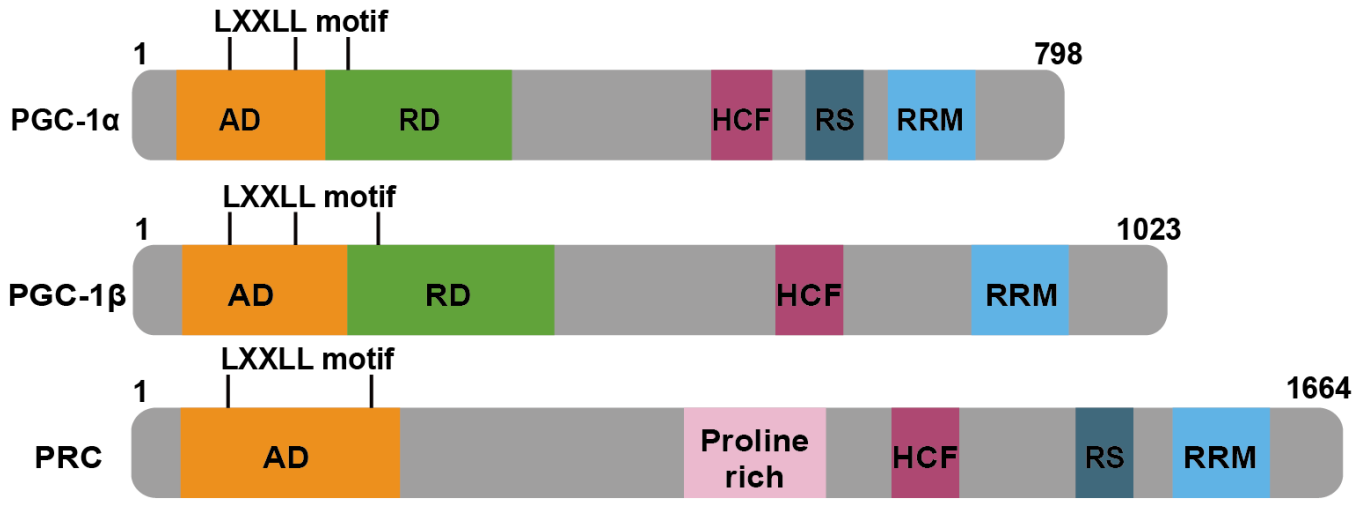

Figure 1. Domain structure of PGC-1 coactivators. The N-terminal region of PGC-1 contains a highly conserved activation domain, responsible for the interaction with coactivator complexes. Adjacent to the N-terminal region is a domain involved in the inhibition of PGC-1 activity. Moreover, the N-terminal domain contains several leucine-rich LXXLL motifs. The C-terminal region of PGC-1 contains several domains that play important roles in mRNA splicing, including RS and RRM. The C-terminal moiety also contains HCF binding site, which is implicated in cell cycle regulation and can regulate PGC-1 activity. In addition, proline-rich region is a domain involved in multiple protein associations. 
response element-binding protein (CREB)-binding protein/p300 (CBP/p300) and steroid receptor coactivator-1 (SRC-1) (Puigserver et al., 1999). These HAT complexes promote the remodeling of histones within chromatin, which facilitate the access of transcriptional machinery to target genes. Although CBP/p300 and members of the p160/SRC family have intrinsic HAT activity that promotes chromatin remodeling and gene transcription, the PGC-1 family members lack such enzymatic activity (Scarpulla, 2011). Moreover, their N-terminal domains contain several leucine-rich LXXLL motifs, namely nuclear receptor (NR) boxes. NR boxes have the crucial function of mediating the interactions of PGC-1 proteins with the hydrophobic pockets of the ligand-binding domains of a wide variety of hormone NRs. Adjacent to the N-terminal region of PGC-1s is a domain of $\sim 200$ amino acids involved in the inhibition of their activity. A second activating complex that docks on the C-terminal domains of PGC-1s, namely the thyroid hormone receptor-associated protein/vitamin $D$ receptorinteracting protein (TRAP/DRIP) complex, is responsible for activation of DNA transcription (Wallberg et al., 2003). Furthermore, the C-terminal regions of PGC-1s contain several domains that play important roles in mRNA splicing, including the serine/arginine-rich stretch (RS) domain and RNA recognition motif (RRM) (Monsalve et al., 2000). Their C-terminal moieties also contain two very wellconserved motifs of unknown functions. One of the two motifs consists of a DHDY tetrapeptide, and it has been identified as a binding site for host cell factor (HCF), the binding of which enhances PGC-1 transcriptional activity and further regulates gene expression during cell cycle progression. In addition, several interaction sites for other transcription factors have also been mapped to the C-terminal regions of PGC-1 proteins, such as myocyte enhancer factor 2C (MEF2C), PPARc, yin yang-1 (YY1) and forkhead box $\mathrm{O1}$ (FoxO1), in addition to co-regulators, such as mediator complex subunit 1 (MED1) and BRG1-associated factor 60a (BAF60a) (Villena, 2015).

\subsection{Regulation of $P G C-1$}

PGC-1 $1 \alpha$ expression is highly inducible at the transcriptional level in response to a variety of upstream signaling pathways. (Figure 2) For instance, PGC-1a gene expression in cardiac myocytes can be modulated by $\mathrm{Ca}^{2+} /$ calmodulindependent protein kinase (CAMK), calcineurin (Schaeffer et al., 2004), AMP-activated protein kinase (AMPK) (Zhu et al., 2010), $\beta$-adrenergic receptor ( $\beta-A R) / c A M P$ (Watson et al., 2007), nitric oxide (NO) (Koka et al., 2014), and autoregulatory positive feedback by PGC-1 $\alpha$ itself (Handschin et al., 2003). The underlying mechanism involves the transduction of these upstream mediators in variable forms of cardiac stress, which results in the regulation of PGC-1a gene expression by transcription factors, such as CREB and MEF2. In addition, PGC-1 $\alpha$ can be induced by some external stimuli that increase energy demand and ATP

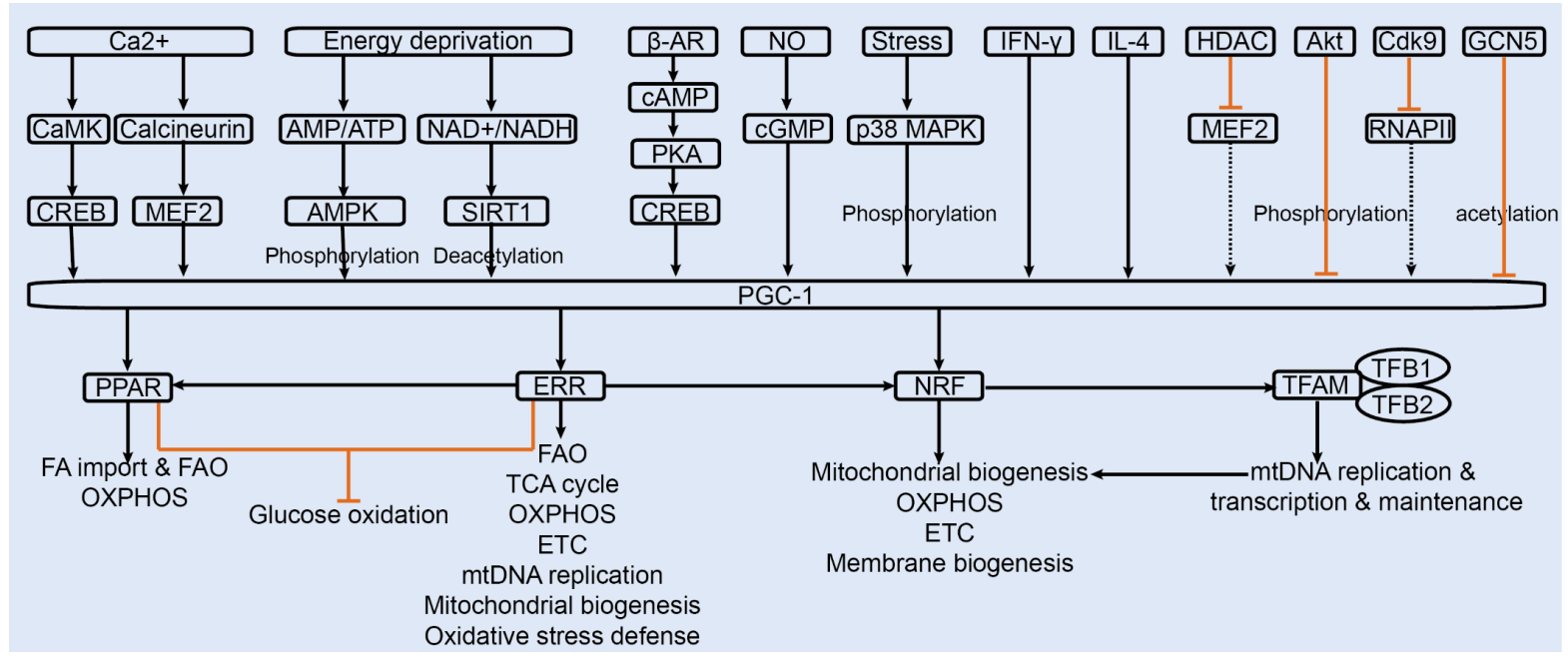

Figure 2. PGC-1 signaling pathways. The schematic indicates the potential upstream regulators of PGC-1, a variety of downstream target genes, and their related effects implicated in the cardiac system. 
production, such as fasting, exercise, and cold exposure. On the other hand, a number of molecules suppress PGC-1a gene expression. For example, class II histone deacetylases (HDACs) inhibit the $P G C-1 \alpha$ promoter by suppressing MEF2 activity, which plays a critical role in maintenance of cardiac mitochondrial function (Czubryt et al., 2003). Moreover, RNA polymerase II (RNAPII) can be phosphorylated by cyclin-dependent kinase 9 (Cdk9), which blocks the recruitment of RNAPII and the general transcription factor TATA-binding protein (TBP) to the endogenous $P G C-1$ promoter and impedes assembly of the PGC-1 pre-initiation complex, leading to mitochondrial dysfunction in the heart (Sano et al., 2004). Thus, PGC-1 $\alpha$ expression is regulated by multiple signals that integrate important cardiometabolic states.

PGC-1 $\alpha$ is also widely regulated at the posttranslational level via protein modifications, such as phosphorylation, acetylation, methylation, ubiquitination, and small ubiquitin-related modifier (SUMO)ylation. Importantly, protein modifications not only regulate the activities of PGC-1s but also adjust them according to specific gene programs by regulating their interactions with specific transcriptional regulators. For example, PGC-1a can be phosphorylated directly by AMPK and p38 mitogen-activated protein kinase (MAPK), which further stimulate its transactivation activity and inhibit its degradation (Gundewar et al., 2009; Scharf et al., 2013; Yu et al., 2017). AMPK also facilitates the activation of silent information regulator 1 (SIRT1), which further increases PGC-1 $\alpha$ transcriptional activity (Canto et al., 2009; Jiang et al., 2017; Liang et al., 2017). Conversely, PGC- $1 \alpha$ activity can be inhibited by Akt-mediated phosphorylation (Whittington et al., 2013). The underlying mechanisms may involve the direct phosphorylation of PGC-1 $\alpha$ by Akt, which prevents the recruitment of PGC- $1 \alpha$ to its cognate promoter regions (Li et al., 2007). In addition, multiple sites of PGC-1a can be acetylated, which has a negative effect on its transcriptional activity. Accumulating evidence suggests that PGC-1 $\alpha$ acetylation is largely modulated by the balance between general control non-derepressible 5 (GCN5) and SIRT1 (Schilling et al., 2011). GCN5 is an acetyltransferase that are involved in the repression of PGC-1 $1 \alpha$ by binding to 13 conserved arginines in PGC-1a (Lerin et al., 2006). However, SIRT1 is induced by an increase in the nicotinamide adenine dinucleotide $\left(\mathrm{NAD}^{+}\right)$level in the presence of reduced cellular energy stores (Zhang et al., 2017). SIRT1 binds to $P G C-1 \alpha$ in the central regulatory region between amino acids 200 and 400 and subsequently deacetylates PGC-1 $\alpha$, thereby promoting the production of ATP and reducing equivalents via mitochondrial substrate oxidation (Schilling et al., 2011). In addition to phosphorylation and acetylation, PGC-1 $\alpha$ also undergoes methylation at several arginine residues in the $\mathrm{C}$-terminal domain by protein arginine methyltransferase 1 (PRMT1) (Teyssier et al., 2005). Arginine methylation has been implicated in the regulation of many cellular processes that involve chromatin remodeling and transcriptional activation. In addition, PGC-1 $\alpha$ can be SUMOylated, which attenuates its transcriptional activity (Rytinki et al., 2009). Therefore, PGC-1 $\alpha$ expression can be regulated by various upstream signaling pathways at both the transcriptional and post-translational levels.

In contrast, the other two members of the PGC-1 family are generally less inducible. Changes in PGC-1 $\beta$ expression have been observed in differentiating osteoclasts, whereas the PRC level changes with cell cycle progression (Andersson et al., 2001; Vercauteren et al., 2009; Wei et al., 2010). Recent studies have demonstrated that interferon- $\gamma$ (IFN- $\gamma$ ) and interleukin-4 (IL-4) activate the PGC-1 $\beta$ promoter via signal transducers and activators of transcription 1 (STAT1) and STAT6, respectively (Vats et al., 2006; Sonoda et al., 2007). Similar to PGC-1 $\alpha$, PGC-1 $\beta$ has recently been demonstrated to be negatively regulated by acetylation (Kelly et al., 2009). However, post-translational modifications of PGC-1 $\beta$ and PRC have been studied much less extensively. Above all, the expression of PGC-1 family members is influenced by numerous upstream mediators that are important for mitochondrial biogenesis and metabolism.

\subsection{PGC-1-coactivated targets}

Both PGC- $1 \alpha$ and PGC-1 $\beta$ regulate the expression of a variety of coactivated genes, including nuclear receptors (NRs) (e.g., ERRs and PPARs), non-NRs (e.g., NRFs and MEF2), and other transcription factors. Generally, ligand-activated proteins encoded by PGC-1-coactivated genes regulate virtually all aspects of cardiac mitochondrial energy transformation, and they have been considered to be valuable therapeutic targets for metabolic and cardiac diseases. Because a detailed description of all of the coactivated targets is apparently beyond the limited length of this review, we will focus on several molecules that have been mechanistically implicated in the pathogenesis and progression of cardiac diseases and that may become potential 
therapeutic targets in the future (Table 1 and Figure 2).

\subsubsection{ERRs}

ERRs are a group of transcription factors that include ERRa, ERR $\beta$, and ERR $\gamma$, which activate the expression of a large number of mitochondrial genes that cover many aspects of mitochondrial oxidative metabolism, including glucose utilization, FA $\beta$-oxidation (FAO), the tricarboxylic acid (TCA) cycle, and OXPHOS (Laganiere et al., 2004). All these ERRs are abundantly expressed in the heart

Table 1. The target genes and downstream biological effects that are potentially regulated by PGC-1 coactivators in cardiac system.

\begin{tabular}{|c|c|c|c|}
\hline Target genes & Experimental models & Downstream biological effects & Reference \\
\hline ERRa & ERRa-null mouse & $\begin{array}{l}\text { ERRa-null mouse exhibits mild defects but with normal } \\
\text { mitochondrial function }\end{array}$ & (Dufour et al., 2007) \\
\hline ERRa & $\begin{array}{l}\text { ERRa-null mouse subjected to } \\
\text { LV pressure overload }\end{array}$ & $\begin{array}{l}\text { ERRa null results in growth defect with preserved } \\
\text { contractile function, pathologic remodeling in response to } \\
\text { pressure overload, and reduced high-energy phosphate } \\
\text { reserve and ATP synthetic capacity }\end{array}$ & (Huss et al., 2007) \\
\hline ERRY & ERRy-null mouse & $\begin{array}{l}\text { ERRy null results in inability to transition from glucose } \\
\text { utilization to FAO, lactatemia, electrocardiographic } \\
\text { abnormalities, cardiomyopathy, and death shortly after birth }\end{array}$ & (Alaynick et al., 2007) \\
\hline PPARa & $\begin{array}{l}\text { Cardiac-restricted } \\
\text { overexpression of PPAR } \\
\text { (MHC-PPAR) mouse }\end{array}$ & $\begin{array}{l}\text { Increased myocardial FAO rates and decreased glucose } \\
\text { uptake and oxidation }\end{array}$ & (Finck et al., 2002) \\
\hline PPARa & MHC-PPARa mouse & $\begin{array}{l}\text { Increased PPARa activity in the diabetic heart leads to } \\
\text { defects in insulin signaling and STAT3 activity, } \\
\text { cardiac insulin resistance, and reduced cardiac function }\end{array}$ & (Park et al., 2005) \\
\hline PPARa & ERRa overexpression mouse & $\begin{array}{l}\text { ERR } \alpha \text { activates PPAR } \alpha \text { expression via direct binding of } \\
\text { ERRa to the PPAR gene promoter, which further } \\
\text { increases cellular FAO rates }\end{array}$ & (Huss et al., 2004) \\
\hline PPAR $\beta / \delta$ & $\begin{array}{l}\text { Transgenic mouse model that } \\
\text { PPAR } \beta / \delta \text { is constitutively } \\
\text { activated in cardiomyocytes }\end{array}$ & $\begin{array}{l}\text { Upregulation of mitochondrial biogenesis and defense, and } \\
\text { oxidative metabolism at basal and pressure- } \\
\text { overload conditions }\end{array}$ & (Liu et al., 2011) \\
\hline PPAR $\beta / \delta$ & MHC-PPAR $\beta / \delta$ mouse & $\begin{array}{l}\text { Increased myocardial glucose utilization, not accumulated } \\
\text { myocardial lipid, and normal cardiac function }\end{array}$ & (Burkart et al., 2007) \\
\hline PPAR $\beta / \delta$ & $\begin{array}{l}\text { MHC-PPAR } \beta / \delta \text { mouse } \\
\text { subjected to I/R injury }\end{array}$ & $\begin{array}{l}\text { Increased capacity for myocardial glucose utilization and } \\
\text { reduced myocardial injury following I/R injury }\end{array}$ & (Burkart et al., 2007) \\
\hline PPARס & PPARס-knockout mouse & $\begin{array}{l}\text { Substantial transcriptional downregulation of lipid metabolic } \\
\text { proteins, reduced rates of palmitate and glucose oxidation, } \\
\text { amelioration of cardiac expression of endogenous } \\
\text { antioxidants, increased oxidative damage to the heart, and } \\
\text { cardiac hypertrophy }\end{array}$ & (Wang et al., 2010) \\
\hline PPARס & $\begin{array}{l}\text { Cardiomyocyte- } \\
\text { restricted deletion of PPAR } \delta \\
\text { mouse }\end{array}$ & $\begin{array}{l}\text { Decreased myocardial FAO, cardiac dysfunction, } \\
\text { progressive myocardial lipid accumulation, cardiac } \\
\text { hypertrophy, lipotoxic cardiomyopathy, congestive heart } \\
\text { failure, and reduced survival }\end{array}$ & (Cheng et al., 2004) \\
\hline PPARY & $\begin{array}{l}\text { Cardiomyocyte-specific PPARY- } \\
\text { knockout mouse }\end{array}$ & $\begin{array}{l}\text { Suppressed Akt phosphorylation, inhibited cardiac growth } \\
\text { and embryonic gene expression, suppressed NF-kB } \\
\text { activity, cardiac hypertrophy, and preserved } \\
\text { systolic cardiac function }\end{array}$ & (Duan et al., 2005) \\
\hline NRF-1 & NRF-1 disruption mouse & $\begin{array}{l}\text { Impaired mitochondrial membrane potential and decreased } \\
\text { mtDNA content }\end{array}$ & (Huo et al., 2001) \\
\hline TFAM & TFAM disruption mouse & $\begin{array}{l}\text { Mosaic cardiac-specific progressive respiratory chain } \\
\text { deficiency, dilated cardiomyopathy, blocked } \\
\text { atrioventricular heart conduction, and death at 2-4 weeks of } \\
\text { age }\end{array}$ & (Wang et al., 1999) \\
\hline TFAM & $\begin{array}{l}\text { Transgenic mouse } \\
\text { overexpressing human TFAM }\end{array}$ & $\begin{array}{l}\text { Amelioration of the decrease in mtDNA copy number and } \\
\text { mitochondrial complex enzyme activities, higher survival } \\
\text { rate, improved LV function, and decreased myocardial } \\
\text { hypertrophy, apoptosis, interstitial fibrosis and oxidative } \\
\text { stress }\end{array}$ & (Ikeuchi et al., 2005) \\
\hline \multicolumn{4}{|c|}{$\begin{array}{l}\text { Abbreviations: PGC-1, peroxisome proliferator activated receptor (PPAR)-Y coactivator-1; ERR, estrogen related receptor; LV, left } \\
\text { ventricular; FAO, fatty acid (FA) } \beta \text {-oxidation; TAC, transverse aortic constriction; MHC-PPAR, myosin heavy chain-PPAR; STAT3, } \\
\text { signal transducers and activators of transcription 3; I/R, ischemia/reperfusion; NF-KB: nuclear factor-kB; NRF-1, nuclear respiratory } \\
\text { factor-1; mtDNA, mitochondrial DNA; TFAM, transcription factor A, mitochondrial. }\end{array}$} \\
\hline
\end{tabular}


and are regulated by PGC-1a. Notably, PGC-1a regulates not only the activity of ERRa but also its expression (Schreiber et al., 2003). The associated mechanism involves the binding of ERRa to conserved ERR response elements (ERREs) in its own promoter, thereby inducing its transcription in a positive autoregulatory loop once it is activated by PGC-1a (Laganiere et al., 2004). ERRs have been demonstrated to act as nonobligatory heterodimers and to target a common set of promoters involved in cardiac mitochondrial energetic pathways through the coactivation of PGC-1a (Dufour et al., 2007). Conversely, PGC-1-independent ERRa expression fails to induce target gene expression (Schreiber et al., 2004). Huss and colleagues have studied the role of the PGC-1a-ERR $\alpha$ signaling pathway in a mouse model subjected to left ventricular pressure overload and have revealed that ERRa is required for the adaptive response to hemodynamic stressors (Huss et al., 2007). ERRa suppression can lead to decompensated heart failure, the underlying mechanisms of which may involve myocardial phosphocreatine depletion and reduced maximal ATP synthesis. Furthermore, ERRY knockout mice display downregulation of several ERR target genes in the heart, such as Ghrpr, Eno1, and $H 6 p d$, reflecting the inability to transition from glucose utilization to FA utilization, which eventually leads to cardiomyopathy and subsequently to death shortly after birth (Alaynick et al., 2007). It is noteworthy that ERRa and ERRY exhibit a compensatory effect in the heart. Dufour and colleagues have found that PGC-1 $\alpha$ and ERRY are upregulated in the $E R R \alpha$ knockout heart, which exhibits only mild defects and normal mitochondrial function under physiological conditions (Dufour et al., 2007) and more severe phenotypes under pathological conditions such as pressure overload, with dilated hypertrophy or early heart failure, possibly caused by decreased energy reserves (Huss et al., 2007). Similar to the deletion of ERRa, that of ERRy promotes the upregulation of PGC-1a and ERR $\alpha$ and hence alters the expression of OXPHOS genes, causing severe mitochondrial defects and eventually the death of most ERRY knockout mice due to failure of the postnatal transition to oxidative FA metabolism in the heart (Alaynick et al., 2007). ERR $\beta$ is the least studied among the three ERRs, and its role in regulating mitochondrial function in the heart is unclear. Shortly, diverse PGC-1-activated ERRs have a compensatory effect and they are the master executors controlling the mitochondrial biogenic gene network in the heart. Activating PGC-1-ERR signaling pathway may present an emerging avenue for the treatment of cardiac diseases.

\subsubsection{PPARs}

PPARs, including PPARa, PPAR $\beta / \delta$, and PPAR $\gamma$, are members of the extended nuclear hormone receptor family (Issemann et al., 1990). All these PPARs are known to play essential roles in the regulation of FA uptake and oxidation in the heart. PGC-1a-activated PPARs form heterodimers with retinoic acid-activated receptors (RXRs) and bind to a specific DNA sequence or PPAR response element (PPRE) to regulate genes involved in FA metabolism (Huss et al., 2004; Rowe et al., 2010). Cardiac overexpression of PPAR $\alpha$ induced by PGC-1 dysregulation causes increased FA uptake and oxidation and concomitantly decreased glucose oxidation, which can lead to spontaneous left ventricular dysfunction and lipotoxic cardiomyopathy (Finck et al., 2002; Park et al., 2005). In contrast to PPARa, cardiac overexpression of $P P A R \beta / \delta$ is relatively protective against lipotoxic cardiomyopathy and myocardial infarction (MI) (Wang et al., 2010; Liu et al., 2011). The differences in the effects of $P P A R \alpha$ and $P P A R \beta / \delta$ overexpression may result from the failure of $P P A R \beta / \delta$ overexpression to induce FA import genes, such as cluster of differentiation 36 (CD36), thereby preventing the toxic accumulation of intracellular lipids (Burkart et al., 2007). On the other hand, inhibition of the PGC-1a-PPAR signaling pathway can result in decreased expression of FAO genes, which eventually leads to a series of cardiac disorders, such as cardiac dysfunction and lipotoxic cardiomyopathy (Cheng et al., 2004; Duncan et al., 2010; Wang et al., 2010). The underlying mechanism may involve a shift in substrate utilization from mainly FAO toward glucose oxidation, leading to less $\mathrm{O}_{2}$ consumption per ATP produced. The role of cardiac PPARY is less well understood. Although PPARY is expressed in the heart at a level far below PPAR $\alpha$ and PPAR $\beta / \delta$, cardiac overexpression or deletion of PPARY also has many detrimental effects on the heart, such as myocardial hypertrophy and heart failure (Duan et al., 2005). Therefore, these findings strongly indicate that the maintenance of balanced levels and activities of PPARs is critical for proper cardiac function in mouse PPARs genetic models. However, homozygous knockout and transgenic expression models are at the ends of the spectrum of experimental modulation. In the case of clinically relevant pharmacological therapeutics, there appears to be a therapeutic window for the use of PPARY agonists, such as thiazolidinediones (TZDs), 
for type 2 diabetes at concentrations that have little if any direct effects on the heart (Zhu et al., 2013).

Interestingly, PPARa is in turn capable of activating the $P G C-1 \alpha$ promoter in certain cell types, indicating that an autoregulatory loop exists between PPAR $\alpha$ and PGC-1a (Duncan et al., 2010). Moreover, as the PPAR $\alpha$ promoter contains a functional ERRE, PPARa expression can be activated by ERRa, which provides an additional site of cross-regulation (Huss et al., 2004). Furthermore, the presence of PPAR $\alpha$ is required for the ERRa-mediated regulation of a series of FAO targets in MEFs (Giguere, 2008). Thus, these data underscore the existence of multiple positive feedback loops that drive metabolic gene expression pathways in the heart.

\subsubsection{NRFs}

Two NRF isoforms, termed NRF-1 and NRF-2 (also known as GABP), are the first vertebrate regulatory factors implicated in the global expression of genes involved in multiple mitochondrial functions (Virbasius et al., 1993; Virbasius et al., 1993). NRFs regulate the expression of nuclear genes required for mitochondrial OXPHOS. Mitochondria are composed of over 1,500 proteins that are encoded by both mtDNA and nuclear DNA (nDNA). The mitochondrial genome contains 37 genes encoding 22 transfer RNAs (tRNAs), 2 ribosomal RNAs (rRNAs), and 13 subunits present in complexes I, III, IV, and V. Apart from these, all the other mitochondrial proteins are encoded by nDNA. Notably, crosstalk occurs between mtDNA and nDNA via nuclear-encoded proteins, including mitochondrial transcription factor $A$ (TFAM) and mitochondrial transcription factor $B$ (TFBM), both of which are induced by PGC-1a-activated NRFs (Pohjoismaki et al., 2012; Villena, 2015). Once NRFs are activated, TFAM subsequently binds to both strands of mtDNA, and it is essential for mtDNA replication, transcription, and maintenance (Kukat et al., 2013). Both an impaired mitochondrial membrane potential and a decreased mtDNA content have been observed in a NRF-1 knockout model, implying that NRF-1 has a role in stabilizing mitochondrial function as a coactivated effector of PGC-1 activation (Huo et al., 2001). Additional studies have shown that TFAM deletion in cardiac tissue results in a significant decrease in the electron transport capacity and mtDNA content, which further causes cardiomyopathy and heart failure (Wang et al., 1999). Conversely, increased TFAM expression in cardiac tissue plays a protective role against heart failure induced by $\mathrm{MI}$
(Ikeuchi et al., 2005). These results indicate that stimulation of the PGC-1 $\alpha$ signaling pathway may protect against cardiac diseases via the activation of NRFs. On the other hand, NRFs also control the expression of nuclear genes encoding respiratory chain subunits and other proteins required for mitochondrial function. For instance, NRF-1 can induce MEF2 to coordinate the expression of mitochondrial respiratory chain subunits (Ramachandran et al., 2008). Along with the direct regulation of PGC-1a by MEF2A, this network provides a positive feedback loop through NRF-1, MEF2A, and PGC-1a to control mitochondrial function and content in cardiac myocytes (Aubert et al., 2013).

\section{Role of PGC-1 in cardiac metabolism}

\subsection{Mitochondrial biogenesis}

Both PGC- $1 \alpha$ and PGC-1 $\beta$ are highly expressed in cardiac myocytes and have been confirmed to be key factors for myocardial mitochondrial biogenesis. Cardiac PGC-1a potently induces mitochondrial biogenesis in both cell culture and transgenic animals (Patten et al., 2012). PGC-1 $\alpha$ expression in the heart increases significantly at birth, consistent with the metabolic switch from glycolysis to OXPHOS in cardiac myocytes and the burst of mitochondrial oxidative capacity (Martin et al., 2014). However, mitochondrial biogenesis is decreased with aging (Russell et al., 2004). Both PGC-1 $\alpha$ and PGC-1 $\beta$ can coactivate a set of transcription factors, including ERRs, PPARs, NRFs, and likely others, which robustly induce the expression of a large number of nuclear genes that encode almost all mitochondrial proteins involved in FAO, the TCA cycle, and the electron transport chain (ETC). For instance, PGC-1s induce the expression of CD36 and FA transport proteins (FATPs) mainly by co-activating PPARs, which increase FA uptake in cardiac myocytes (Patten et al., 2012). Moreover, PGC-1s regulate FA flux and storage in the process of lipolysis of cellular triglycerides by adipose triglyceride lipase (ATGL) (Haemmerle et al., 2011). FAO in mitochondria generates reducing equivalents and acetyl-CoA, which subsequently enters the TCA cycle and generates additional reducing equivalents to fuel the ETC and ATP synthesis. In addition to nuclearencoded genes, mitochondrial biogenesis requires the replication and transcription of the mitochondrial genome itself. The activation of TFAM, TFBM, and mitochondrial polymerases by the PGC-1 coactivators may participate in the process. Thus, PGC-1s regulate mitochondrial biogenesis by 
coordinating the expression of mitochondrial proteins encoded by both the nuclear and mitochondrial genomes.

Accumulating loss-of-function studies have shown that $P G C-1 \alpha$ deletion results in the impaired expression of genes involved in OXPHOS and FAO, which leads to a reduced ability to maintain body temperature upon cold exposure. In addition, $P G C$-1 $\alpha$-deficient mice display decreased cardiac energy reserves, a reduced heart rate and contractile function, and impaired inotropic and chronotropic responses. They also respond poorly to physiological and pathophysiologic stresses, such as exercise, fasting, chronic pressure overload, and ischemic insult (Arany et al., 2005; Arany et al., 2006). Moreover, PGC-1 $\alpha$ knockout contributes to the development of cardiomyopathy mainly as the result of a metabolic switch. The related mechanisms could involve reductions in the maximal capacities for mitochondrial ATP synthesis and $F A O$ and an increase in triglycerides due to reduced consumption (Lehman et al., 2008). Several studies have demonstrated that $P G C-1 \beta$ knockout mice have only mildly abnormal cardiac phenotypes, with relatively normal contractile function but impaired chronotropic responses under stressed conditions (Lelliott et al., 2006; Lai et al., 2008). A lack of both $P G C-1 \alpha$ and $P G C-1 \beta$ significantly diminishes the cardiac mitochondrial content, causing mice to die within 24 hours after birth because of heart failure (Lai et al., 2008; Patten et al., 2012). However, the above data came from global PGC-1 knockout mice, so we must take for consideration that the cardiac phenotype might be a consequence of the systemic alterations induced by $P G C-1$ knockout rather than direct cardiac effects. A critical evaluation of the role of $P G C-1 s$ in cardiac function in intact animals thus requires the cardiac-specific knockout of $P G C-1 s$. Fortunately, a recent study has eliminated systemic alterations such as glucose homeostasis induced by inhibition of PGC-1 and its coactivated targets, as evidenced by a distinctive mitochondrial cristaestacking abnormality in the model of cardiac-specific inducible $P G C-1 \alpha / \beta$ double-deficient mouse (Lai et al., 2014). This suggests that PGC-1 $\alpha$ and PGC-1 $\beta$ contribute to mitochondrial structural integrity and function. The integrity and function of mitochondrion in the heart also depend partly on its membrane structure, including cardiolipin. A genetic defect in cardiolipin remodeling leads to modification in mitochondrial ultrastructure and function. Therefore, $P G C-1 \alpha$ and $P G C-1 \beta$ regulate mitochondrial structural integrity and function by regulating phospholipid synthesis. These results suggest that PGC-1 $\alpha$ and PGC-1 $\beta$ have synergetic functions and collectively support mitochondrial biogenesis in the heart.

Conversely, increasing gain-of-function studies have shown that PGC-1 $\alpha$ is a powerful driver of cardiac mitochondrial biogenesis (Villena, 2015) and that the complex effects may vary dramatically between neonatal and adult hearts. PGC- $1 \alpha$ overexpression in rat neonatal cardiac myocytes is beneficial, as demonstrated by increases in mitochondrial biogenesis, oxygen consumption, and coupled respiration. However, its overexpression in the adult mouse heart leads to uncontrolled mitochondrial biogenesis, aberrant mitochondrial structures, and reversible dilated cardiomyopathy, which can be completely reversed when PGC-1 $1 \alpha$ expression is knocked out (Lehman et al., 2000; Russell et al., 2004). Although increased mitochondrial biogenesis provides benefits to the heart, it is important to carefully maintain PGC-1 $\alpha$ expression at a moderate level to prevent adverse effects. Notably, PGC-1 $\beta$ overexpression in the adult heart does not appear to cause cardiac dysfunction. In fact, PGC-1 $\beta$ overexpression prevents cardiac dysfunction in a model of septic cardiomyopathy (Schilling et al., 2011). Therefore, ectopic expression of PGC-1 $\beta$ seems to be safer.

\subsection{Fuel shift}

As a self-renewing biological pump, the heart converts chemical energy into mechanical energy by utilizing the most efficient fuel to produce ATP for contraction. The sources of ATP the heart needs are diverse, which come from FAs, glucose, lactate, ketone bodies, and (under extreme circumstances) amino acids. To secure the availability of energy substrates, the heart has developed into a "metabolic omnivore" where the source of ATP production can be changed from one fuel to another (Baskin et al., 2011). During fetal development, the heart primarily consumes glucose and lactate due to relatively hypoxic environment and lower FA levels (Rowe et al., 2010). Soon after birth, heart function significantly improves as exposed to an oxygen-rich environment, consistent with the activation of multiple genes involved in FA transport and FAO by long-chain FAs contained in maternal milk (Janssen et al., 2014); thus, a dramatic shift in fuel utilization occurs from glucose and lactate oxidation toward high reliance on mitochondrial FAO (Lai et al., 2008). Emerging evidence suggests that PGC-1 coactivators play a pivotal role in the shift of substrate utilization. The PGC-1s mainly interact 
with PPARa, and further mediate this shift (Taegtmeyer et al., 2010). It has recently been shown that FAs liberated from the triacylglyceride pool by the actions of ATGL are also required to activate PPARa signaling (Carley et al., 2014). Overall, perinatal changes in myocardial metabolism are mainly driven by the activation of the PPARa by long-chain FAs, which are contained in maternal milk.

When subjected to pathological conditions such as myocardial hypertrophy and heart failure, there is a mismatch among FA uptake, triacylglyceride turnover, and PPAR $\alpha$ activation (Carley et al., 2014). Increasing studies have indicated that a shift away from FAO and back to glucose oxidation occurs partly due to the downregulation of PGC-1 $\alpha$ and its coactivated targets, such as PPARs (Huss et al., 2007; Abel et al., 2011). On the other hand, glucose oversupply results in the activation of mTOR pathway (Kundu et al., 2015). In an effort to maintain a delicate balance between energy transformation and utilization, this fuel shift may initially serve as an adaptive transition and play a compensatory role in meeting the energy demands of contraction by adapting metabolic machinery of heart. However, over a long period of time, this metabolic shift may be maladaptive and ultimately lead to energy starvation and cardiac diseases (Schilling et al., 2011; Kundu et al., 2015). Indeed, studies of animal models and humans have shown that high-energy phosphate reserves are reduced in the hypertrophied and failing hearts. Moreover, increased myocardial glucose uptake precedes the onset of left ventricular hypertrophy and heart failure (Sen et al., 2013). Furthermore, early intervention to attenuate glucose uptake can prevent the maladaptive metabolic response and preserve cardiac function (Kundu et al., 2015). Therefore, glycometabolic disorder is a prominent feature of the maladapted failing heart.

Collectively, the PGC-1 coactivators are important regulators of the fuel shift in the courses of both physiological and pathological conditions. Targeting the fuel shift may offer new opportunities to rebuild the hypertrophied and failing hearts, however, several unresolved questions remain to be more completely answered. For example, is the fuel shift simply a phenomenon accompanying the progression of underlying diseases? Alternatively, does it contribute to pathological remodeling?

\subsection{Reactive oxygen species (ROS)}

Mitochondrial activity inevitably generates toxic byproducts, such as ROS, which can lead to heart failure, atherosclerosis, and diabetes (Schilling et al., 2011). Excessive production of ROS in the myocardium is a leading cause of oxidative stress, resulting in myocardial damage. The major site of ROS generation in most cells is the mitochondrial ETC (Ma et al., 2017). Electrons exit the ETC and interact with free oxygen, which further yields partially reduced oxygen species that are highly reactive (Patten et al., 2012). The expression of PGC-1 has been demonstrated to increase by physical exercise even in rat cardiac muscle and is restored to control levels by the antioxidant treatment (Venditti et al., 2016). Moreover, several lines of evidence suggest that PGC- $1 \alpha$, which is closely associated with the ETC, transcriptionally modifies pathways involved in ROS production or scavenging in the heart (Lu et al., 2010). PGC-1a can efficiently scavenge ROS by reducing the mitochondrial membrane potential, which decreases oxidative stress in the mitochondria and thus plays a protective role against cardiac diseases such as myocardial ischemia/reperfusion (I/R) injury (McLeod et al., 2005). The related mechanism may involve the expression of several uncoupling proteins (UCPs) partly induced by PGC-1a, which are inner mitochondrial membrane proteins that dissipate the protein gradient across the inner mitochondrial membrane (Girnun, 2012). Furthermore, the PGC-1-NRF signaling pathway mediates antioxidant gene expression. The selective functional incapacity of NRFs has been demonstrated to result in failure to maintain mitochondrial DNA (mtDNA) replication and OXPHOS gene expression, which contributes to increased ROS generation in infected cardiac myocytes (Wan et al., 2012). Moreover, PGC-1 coactivators induce ROS scavengers, such as superoxide dismutase 1 (SOD1), SOD2, catalase, and glutathione peroxidase 1 (GPX1), which counterbalance the release of ROS or transform them into less reactive species upon oxidant stress (Sun et al., 2014). Overall, PGC-1 coactivators modulate oxidative stress generation, suggesting that targeting these coactivators in cardiac myocytes may be a novel therapeutic approach for the prevention and treatment of myocardial damage.

\section{Significant treatments that target the PGC-1 signaling pathway}

PGC-1a has been reported to play a critical role in cardioprotective therapies. A summary of several significant cardiac disease treatments targeting the PGC-1 signaling pathways, including medications, exercise training, and caloric restriction, are presented in Table 2. 


\subsection{Treatment with medication}

Medications that target PGC-1 signaling pathways may be useful for the alleviation and prevention of cardiac diseases. Losartan is an angiotensin II receptor antagonist with antihypertensive activity. It has been widely accepted that the activity and expression of PGC-1 $\alpha$ and left ventricular function are markedly suppressed following acute MI (AMI). Sun and colleagues have found that losartan increases PGC-1 $\alpha$ gene expression, which further ameliorates the adverse effects of $\mathrm{AMI}$ and preserves left ventricular function (Sun et al., 2007). Additionally, catecholamine, a class of hormones and drugs used for the treatment of end-stage heart failure, might stimulate PGC-1 $\alpha$ expression via cAMP-mediated mechanisms (Puigserver et al., 1998). Bezafibrate, a PPAR pan-agonist used clinically to treat hyperlipidemia by increasing FAO, has also been shown to increase PGC-1a expression and mitochondrial biogenesis. Bezafibrate reduces the risks of developing coronary heart disease and $\mathrm{MI}$ and the incidence of cardiac mortality in metabolic syndrome patients. However, further studies are needed because bezafibrate has low potency and possible toxic effects (Dillon et al., 2012). Fenofibrate, a nonselective PPAR agonist, can restore cardiac expression of PGC-1 $\alpha$ and $P G C-1 \beta$, which reverse systemic lipid accumulation, normalize oxidative

Table 2. Effects of the regulation of PGC-1 coactivators in cardiac diseases.

\begin{tabular}{|c|c|c|c|c|}
\hline Treatment & & Diseases & Effects & Reference \\
\hline \multirow[t]{9}{*}{ Medication } & Losartan & $\mathrm{MI}$ & $\begin{array}{l}\text { Losartan increases PGC-1 } 1 \alpha \text { expression, reserves } \\
\text { the adverse effects of } \mathrm{MI} \text {, and preserves left } \\
\text { ventricular function }\end{array}$ & (Sun et al., 2007) \\
\hline & Catecholamine & Heart failure & $\begin{array}{l}\text { Catecholamine stimulates PGC-1a expression } \\
\text { via cAMP-mediated mechanisms }\end{array}$ & (Puigserver et al., 1998) \\
\hline & Bezafibrate & $\begin{array}{l}\text { Coronary heart } \\
\text { disease and } \mathrm{MI}\end{array}$ & $\begin{array}{l}\text { Increased PGC-1 } 1 \alpha \text { expression, mitochondrial } \\
\text { biogenesis, and FAO }\end{array}$ & (Dillon et al., 2012) \\
\hline & Fenofibrate & Cardiomyopathy & $\begin{array}{l}\text { Activation of the PGC-1-PPARa signaling } \\
\text { pathway }\end{array}$ & (Haemmerle et al., 2011) \\
\hline & SAL & Myocardial I/R injury & $\begin{array}{l}\text { Activation of the PGC-1a-NRF1/NRF2 signaling } \\
\text { pathway }\end{array}$ & (Ping et al., 2015) \\
\hline & APS & $\begin{array}{l}\text { Iso-induced } \\
\text { myocardial } \\
\text { hypertrophy }\end{array}$ & $\begin{array}{l}\text { TNF- } \alpha \text { inhibition, PGC-1 } 1 \alpha \text { upregulation, improved } \\
\text { energy biosynthesis, and amelioration of } \\
\text { myocardial hypertrophy }\end{array}$ & (Luan et al., 2015) \\
\hline & Pioglitazone & Myocardial I/R injury & $\begin{array}{l}\text { Pioglitazone increases PGC-1a expression, } \\
\text { suppresses myocardial apoptosis, } \\
\text { and decreases infarct size }\end{array}$ & (Shen et al., 2014) \\
\hline & Diazoxide & Myocardial I/R injury & $\begin{array}{l}\text { Pretreatment with diazoxide protects } \\
\text { myocardial mitochondria against I/R injury by } \\
\text { mimicking IPC and the mechanism of action may } \\
\text { involve the activation and overexpression } \\
\text { of PGC- } 1 \alpha\end{array}$ & (Han et al., 2010) \\
\hline & CVB-D & $\begin{array}{l}\text { DOX-induced } \\
\text { cardiomyopathy }\end{array}$ & $\begin{array}{l}\text { Pretreatment with CVB-D inhibits the repression } \\
\text { of PGC-1a, NRF-1, and mtDNA copy number, } \\
\text { preserves mitochondrial biogenesis, and } \\
\text { attenuates DOX-induced cardiac contractile } \\
\text { dysfunction and histological alterations }\end{array}$ & (Guo et al., 2015) \\
\hline \multirow[t]{3}{*}{$\begin{array}{l}\text { Exercise } \\
\text { training }\end{array}$} & Aerobic interval training & MI & $\begin{array}{l}\text { Increased nuclear PGC- } 1 \alpha \text { expression and } \\
\text { amelioration of mitochondrial dysfunction }\end{array}$ & (Jiang et al., 2014) \\
\hline & $\begin{array}{l}\text { A 3-week swimming } \\
\text { training }\end{array}$ & MI & $\begin{array}{l}\text { A 3-week swimming training increases mtDNA } \\
\text { replication and transcription, reduces myocardial } \\
\text { infarct size, and abolishes MI-induced autophagy } \\
\text { and apoptosis via activating the PGC-1a } \\
\text { signaling pathways }\end{array}$ & (Tao et al., 2015) \\
\hline & $\begin{array}{l}\text { Short-term endurance } \\
\text { exercise training }\end{array}$ & $\begin{array}{l}\text { DOX-induced } \\
\text { cardiomyopathy }\end{array}$ & $\begin{array}{l}\text { Increased PGC-1 } 1 \alpha \text { expression, } \\
\text { decreased FoxO1 and MuRF-1 expression }\end{array}$ & (Kavazis et al., 2014) \\
\hline $\begin{array}{l}\text { Caloric } \\
\text { restriction }\end{array}$ & $\begin{array}{l}\text { Long-term caloric } \\
\text { restriction }\end{array}$ & $\begin{array}{l}\text { Ischemic myocardial } \\
\text { injury }\end{array}$ & $\begin{array}{l}\text { SIRT1 activates both autophagy, by } \\
\text { deacetylating autophagy proteins, and } \\
\text { mitochondrial biogenesis, via activation of } \\
\text { PGC-1a }\end{array}$ & (Carreira et al., 2011) \\
\hline
\end{tabular}

Abbreviations: PGC-1, peroxisome proliferator activated receptor (PPAR)-y coactivator-1; MI, myocardial infarction; mtDNA, mitochondrial DNA; DOX, doxorubicin; FoxO1, forkhead box O1; MuRF-1, muscle ring finger-1. 
function in mitochondria, improve cardiac performance, and prevent lethal cardiomyopathy. Exogenous FAs are activated and then either enter mitochondria for oxidation or become re-esterified and stored within lipid droplets after entering the cell. ATGL-mediated hydrolysis of TG stores provides ligands for functional signaling by the PGC-1-PPARa complex, which activates mitochondrial biogenesis and OXPHOS (Haemmerle et al., 2011). This opens the possibility of clinical application of activating PGC-1-PPARa signaling pathway for the treatment of patients with neutral lipid storage disease with myopathy. Salidroside (SAL), an effective extracted component from $R$. crenulata, is a traditional Chinese medicine that has been recognized as a plant-derived adaptogen capable of maintaining physiological homeostasis upon exposure to stress. Accumulating evidence suggests that SAL has protective effects on many cardiac diseases such as myocardial I/R injury (Xu et al., 2013). Recently, Ping and colleagues have demonstrated that SAL improves myocardial mitochondrial respiratory function by stimulating the expression of PGC-1a-NRF-1/NRF-2 pathway during cardioprotection (Ping et al., 2015). Therefore, SAL may be a novel treatment option for the prevention and treatment of myocardial damage. In conclusion, all these data indicate that activation of the PGC-1 signaling pathways confers benefits to the impaired heart. However, there clearly are limited drugs that activate PGC-1 and all have pleiotropic effects beyond PGC-1 activation; thus, the nature and frequency of safety problems that might occur remain a mystery.

\subsection{Exercise training treatment}

Accumulating studies suggest that the protective role of exercise training in cardiac diseases may involve the activation of PGC-1 $\alpha$ expression. It has been demonstrated that aerobic interval training suppresses pathological remodeling via promotion of nuclear PGC-1a expression, thus inhibiting mitochondrial dysfunction following $\mathrm{MI}$ in rats (Jiang et al., 2014). In another study on the effect of exercise training, Tao and colleagues have used a C57BL/6 mouse model of AMI induced by left coronary artery (LCA) ligation, which induces a fuel shift from FAO to glucose metabolism in the myocardium, along with the downregulation of PPARa and PPARY. They have reported that 3week swimming training attenuates myocardial infarct size and represses AMI-induced autophagy and apoptosis. The related mechanism may involve adaptive increases in mtDNA replication and transcription during the acute phase of MI promoted via induction of the PGC-1 $\alpha$ signaling pathways (Tao et al., 2015). It has also been found that shortterm endurance exercise training promotes cardiac PGC-1a expression, protecting against druginduced cardiomyopathy, such as that caused by DOX, a potent antitumor agent used in cancer treatment. These cardioprotective effects of exercise might be attributable to the suppression of FoxO1 activity by increased PGC-1 $\alpha$ expression, which leads to decreased expression of FoxO1 target genes, including MuRF-1 (Kavazis et al., 2014; Xin et al., 2017). These results confirm that exercise training reduces mitochondrial dysfunction in the heart via upregulation of PGC-1 signaling pathways, which provides an emerging approach for the treatment of cardiac diseases. There is no doubt that exercise also activates other pathways that exert PGC-1-independent cardiac protective effect, as evidenced by aerobic interval training that improves myocardial SERCA2a performance. This confers a primary effect on normalization of $\mathrm{Ca}^{2+}$ handling and improvement of contractility of cardiac muscle (Kemi et al., 2008). Another typical example is that exercise training normalizes the expression of adiponectin and its receptors in patients with chronic heart failure, reversing disorders in lipid and glucose metabolism and further exerting beneficial effects (Van Berendoncks et al., 2011).

\subsection{Caloric restriction treatment}

Caloric restriction is also a potential research direction, which improves myocardial ischemic tolerance. Long-term caloric restriction mice exhibit a significant increase in cardiac PGC-1 1 level, supporting optimal energy metabolism and biochemical adaptation, which is necessary for maintaining energy homeostasis (Ranhotra, 2010). The cardioprotection afforded by long-term caloric restriction seems to occur via a NO-dependent increase in nuclear SIRT1 content. A possible mechanism is that SIRT1 activates PGC-1a expression, which improves mitochondrial biogenesis. In addition, SIRT1 can activate autophagy by deacetylating autophagy proteins (Carreira et al., 2011; Yu et al., 2017). These results suggest that caloric restriction ensures good mitochondrial function by promoting mitochondrial turnover via activation of PGC-1a.

\section{Conclusions}

This review elaborates upon the emerging roles of PGC-1 coactivators in cardiac metabolism. In summary, multiple upstream signals and protein modifications regulate the activity and expression of 
PGC-1 coactivators. Upon activation, these coactivators initiate the expression of a number of coactivated genes, such as those encoding ERRs, PPARs, and NRFs, which regulate virtually all aspects of mitochondrial energy transformation in the heart. In addition to regulating mitochondrial biogenesis, PGC-1 coactivators mediate a dramatic fuel shift from glucose oxidation toward FAO, which is reversed in the course of cardiac diseases via regulation of their coactivated targets, PPARs. Moreover, PGC-1 coactivators influence the expression of anti-oxidative enzymes and efficiently scavenge ROS, thereby decreasing oxidative stress in the mitochondria; thus, they play a protective role against myocardial damage. It is well accepted that the activity and expression of PGC- $1 \alpha$ are significantly repressed in the setting of cardiac diseases, accompanied by energetic abnormalities in the heart. The upregulation of PGC-1 signaling pathways appears to be a promising strategy for the alleviation and prevention of cardiac diseases. Moreover, a pre-treatment that targets PGC-1 signaling pathways might effectively protect the myocardium from damage. PGC-1 coactivators, as well as their numerous upstream mediators and coactivated genes, provide researchers with many opportunities to explore therapeutic strategies.

Although enormous evidence has clarified specific underlying mechanisms of cardiac metabolism regarding PGC-1 in cardiac metabolism, the development of successful treatments that target PGC-1 remains in its infancy, and future studies are necessary. Data regarding the pathological implications of PGC-1 coactivators on rodent and human cardiac diseases are restricted, often contradictory and mostly limited to PGC-1a. Future research should focus on illustrating the signaling network of PGC-1 coactivators in cardiac diseases. Moreover, there are still many issues to be resolved. For example, how does the activity and expression of PGC-1 coactivators altered in human cardiac diseases? How could the PGC-1 signaling pathways be controlled in a manner that exerts powerful and highly regulatory effects without causing concurrent adverse side effects? Therefore, prior to the investigation of therapies that target PGC-1 signaling pathway, a more comprehensive and detailed view regarding the role of PGC-1 in cardiac metabolism and cardiac diseases is necessary.

\section{Acknowledgements}

This work was supported by the National Natural Science Foundation of China (81500263) and China
Postdoctoral Science Foundation (2016T90973 and 2015M572681).

\section{References}

Abel, E.D. and Doenst, T. (2011). Mitochondrial adaptations to physiological vs. pathological cardiac hypertrophy. Cardiovascular research 90, 234-242.

Alaynick, W.A., Kondo, R.P., Xie, W., He, W., Dufour, C.R., Downes, M., Jonker, J.W., Giles, W., Naviaux, R.K., Giguere, V., et al. (2007). ERRgamma directs and maintains the transition to oxidative metabolism in the postnatal heart. Cell metabolism 6, 13-24.

Andersson, U. and Scarpulla, R.C. (2001). Pgc-1related coactivator, a novel, serum-inducible coactivator of nuclear respiratory factor 1dependent transcription in mammalian cells. Molecular and cellular biology 21, 3738-3749.

Arany, Z., He, H., Lin, J., Hoyer, K., Handschin, C., Toka, O., Ahmad, F., Matsui, T., Chin, S., Wu, P.H., et al. (2005). Transcriptional coactivator PGC-1 alpha controls the energy state and contractile function of cardiac muscle. Cell metabolism 1, 259-271.

Arany, Z., Novikov, M., Chin, S., Ma, Y., Rosenzweig, A. and Spiegelman, B.M. (2006). Transverse aortic constriction leads to accelerated heart failure in mice lacking PPAR-gamma coactivator 1alpha. Proceedings of the National Academy of Sciences of the United States of America 103, 10086-10091.

Aubert, G., Vega, R.B. and Kelly, D.P. (2013). Perturbations in the gene regulatory pathways controlling mitochondrial energy production in the failing heart. Biochimica et biophysica acta 1833, 840-847.

Baskin, K.K. and Taegtmeyer, H. (2011). An expanded role for AMP-activated protein kinase: regulator of myocardial protein degradation. Trends in cardiovascular medicine 21, 124-127.

Burkart, E.M., Sambandam, N., Han, X., Gross, R.W., Courtois, M., Gierasch, C.M., Shoghi, K., Welch, M.J. and Kelly, D.P. (2007). Nuclear receptors PPARbeta/delta and PPARalpha direct distinct metabolic regulatory programs in the mouse heart. The Journal of clinical investigation 117, 3930-3939.

Canto, C., Gerhart-Hines, Z., Feige, J.N., Lagouge, M., Noriega, L., Milne, J.C., Elliott, P.J., Puigserver, P. and Auwerx, J. (2009). AMPK regulates energy expenditure by modulating NAD + metabolism and SIRT1 activity. Nature 458, 1056-1060. 
Carley, A.N., Taegtmeyer, H. and Lewandowski, E.D. (2014). Matrix revisited: mechanisms linking energy substrate metabolism to the function of the heart. Circulation research 114, 717-729.

Carreira, R.S., Lee, P. and Gottlieb, R.A. (2011). Mitochondrial therapeutics for cardioprotection. Current pharmaceutical design 17, 2017-2035.

Cheng, L., Ding, G., Qin, Q., Huang, Y., Lewis, W., He, N., Evans, R.M., Schneider, M.D., Brako, F.A., Xiao, Y., et al. (2004). Cardiomyocyte-restricted peroxisome proliferator-activated receptor-delta deletion perturbs myocardial fatty acid oxidation and leads to cardiomyopathy. Nature medicine 10 , 1245-1250.

Czubryt, M.P., McAnally, J., Fishman, G.I. and Olson, E.N. (2003). Regulation of peroxisome proliferator-activated receptor gamma coactivator 1 alpha (PGC-1 alpha ) and mitochondrial function by MEF2 and HDAC5. Proceedings of the National Academy of Sciences of the United States of America 100, 1711-1716.

Dillon, L.M., Rebelo, A.P. and Moraes, C.T. (2012). The role of PGC-1 coactivators in aging skeletal muscle and heart. IUBMB life 64, 231-241.

Duan, S.Z., Ivashchenko, C.Y., Russell, M.W., Milstone, D.S. and Mortensen, R.M. (2005). Cardiomyocyte-specific knockout and agonist of peroxisome proliferator-activated receptor-gamma both induce cardiac hypertrophy in mice. Circulation research 97, 372-379.

Dufour, C.R., Wilson, B.J., Huss, J.M., Kelly, D.P., Alaynick, W.A., Downes, M., Evans, R.M., Blanchette, M. and Giguere, V. (2007). Genomewide orchestration of cardiac functions by the orphan nuclear receptors ERRalpha and gamma. Cell metabolism 5, 345-356.

Duncan, J.G., Bharadwaj, K.G., Fong, J.L., Mitra, R., Sambandam, N., Courtois, M.R., Lavine, K.J., Goldberg, I.J. and Kelly, D.P. (2010). Rescue of cardiomyopathy in peroxisome proliferatoractivated receptor-alpha transgenic mice by deletion of lipoprotein lipase identifies sources of cardiac lipids and peroxisome proliferatoractivated receptor-alpha activators. Circulation 121, 426-435.

Finck, B.N., Lehman, J.J., Leone, T.C., Welch, M.J., Bennett, M.J., Kovacs, A., Han, X., Gross, R.W., Kozak, R., Lopaschuk, G.D., et al. (2002). The cardiac phenotype induced by PPARalpha overexpression mimics that caused by diabetes mellitus. The Journal of clinical investigation 109, 121-130.

Giguere, V. (2008). Transcriptional control of energy homeostasis by the estrogen-related receptors. Endocrine reviews 29, 677-696.
Girnun, G.D. (2012). The diverse role of the PPARgamma coactivator 1 family of transcriptional coactivators in cancer. Seminars in cell and developmental biology 23, 381-388.

Gleyzer, N. and Scarpulla, R.C. (2013). Activation of a PGC-1-related coactivator (PRC)-dependent inflammatory stress program linked to apoptosis and premature senescence. The Journal of biological chemistry 288, 8004-8015.

Gundewar, S., Calvert, J.W., Jha, S., Toedt-Pingel, I., Ji, S.Y., Nunez, D., Ramachandran, A., AnayaCisneros, M., Tian, R. and Lefer, D.J. (2009). Activation of AMP-activated protein kinase by metformin improves left ventricular function and survival in heart failure. Circulation research 104, 403-411.

Guo, Q., Guo, J., Yang, R., Peng, H., Zhao, J., Li, L. and Peng, S. (2015). Cyclovirobuxine D Attenuates Doxorubicin-Induced Cardiomyopathy by Suppression of Oxidative Damage and Mitochondrial Biogenesis Impairment. Oxidative medicine and cellular longevity 2015, 151972.

Haemmerle, G., Moustafa, T., Woelkart, G., Buttner, S., Schmidt, A., van de Weijer, T., Hesselink, M., Jaeger, D., Kienesberger, P.C., Zierler, K., et al. (2011). ATGL-mediated fat catabolism regulates cardiac mitochondrial function via PPAR-alpha and PGC-1. Nature medicine 17, 1076-1085.

Han, J.S., Wang, H.S., Yan, D.M., Wang, Z.W., Han, H.G., Zhu, H.Y. and Li, X.M. (2010). Myocardial ischaemic and diazoxide preconditioning both increase PGC-1alpha and reduce mitochondrial damage. Acta cardiologica 65, 639-644.

Handschin, C., Rhee, J., Lin, J., Tarr, P.T. and Spiegelman, B.M. (2003). An autoregulatory loop controls peroxisome proliferator-activated receptor gamma coactivator 1alpha expression in muscle. Proceedings of the National Academy of Sciences of the United States of America 100, 7111-7116.

He, X., Sun, C., Wang, F., Shan, A., Guo, T., Gu, W., Cui, B. and Ning, G. (2012). Peri-implantation lethality in mice lacking the PGC-1-related coactivator protein. Developmental dynamics : an official publication of the American Association of Anatomists 241, 975-983.

Huo, L. and Scarpulla, R.C. (2001). Mitochondrial DNA instability and peri-implantation lethality associated with targeted disruption of nuclear respiratory factor 1 in mice. Molecular and cellular biology 21, 644-654.

Huss, J.M., Imahashi, K., Dufour, C.R., Weinheimer, C.J., Courtois, M., Kovacs, A., Giguere, V., Murphy, E. and Kelly, D.P. (2007). The nuclear receptor ERRalpha is required for the 
bioenergetic and functional adaptation to cardiac pressure overload. Cell metabolism 6, 25-37.

Huss, J.M. and Kelly, D.P. (2004). Nuclear receptor signaling and cardiac energetics. Circulation research 95, 568-578.

Huss, J.M., Torra, I.P., Staels, B., Giguere, V. and Kelly, D.P. (2004). Estrogen-related receptor alpha directs peroxisome proliferator-activated receptor alpha signaling in the transcriptional control of energy metabolism in cardiac and skeletal muscle. Molecular and cellular biology 24, 9079-9091.

Ikeuchi, M., Matsusaka, H., Kang, D., Matsushima, S., Ide, T., Kubota, T., Fujiwara, T., Hamasaki, N., Takeshita, A., Sunagawa, K., et al. (2005). Overexpression of mitochondrial transcription factor a ameliorates mitochondrial deficiencies and cardiac failure after myocardial infarction. Circulation 112, 683-690.

Issemann, I. and Green, S. (1990). Activation of a member of the steroid hormone receptor superfamily by peroxisome proliferators. Nature 347, 645-650.

Janssen, C.I. and Kiliaan, A.J. (2014). Long-chain polyunsaturated fatty acids (LCPUFA) from genesis to senescence: the influence of LCPUFA on neural development, aging, and neurodegeneration. Progress in lipid research 53, 1-17.

Jiang, H.K., Wang, Y.H., Sun, L., He, X., Zhao, M., Feng, Z.H., Yu, X.J. and Zang, W.J. (2014). Aerobic interval training attenuates mitochondrial dysfunction in rats post-myocardial infarction: roles of mitochondrial network dynamics. International journal of molecular sciences 15 , 5304-5322.

Jiang, S., Li, T., Yang, Z., Yi, W., Di, S., Sun, Y., Wang, D. and Yang, Y. (2017). AMPK orchestrates an elaborate cascade protecting tissue from fibrosis and aging. Ageing research reviews 38, 18-27.

Kavazis, A.N., Smuder, A.J. and Powers, S.K. (2014). Effects of short-term endurance exercise training on acute doxorubicin-induced FoxO transcription in cardiac and skeletal muscle. Journal of applied physiology 117, 223-230.

Kelly, T.J., Lerin, C., Haas, W., Gygi, S.P. and Puigserver, P. (2009). GCN5-mediated transcriptional control of the metabolic coactivator PGC-1beta through lysine acetylation. The Journal of biological chemistry 284, 19945-19952.

Kemi, O.J., Ceci, M., Condorelli, G., Smith, G.L. and Wisloff, U. (2008). Myocardial sarcoplasmic reticulum $\mathrm{Ca} 2+$ ATPase function is increased by aerobic interval training. European journal of cardiovascular prevention and rehabilitation : official journal of the European Society of Cardiology, Working Groups on Epidemiology and Prevention and Cardiac Rehabilitation and Exercise Physiology 15, 145-148.

Koka, S., Aluri, H.S., Xi, L., Lesnefsky, E.J. and Kukreja, R.C. (2014). Chronic inhibition of phosphodiesterase 5 with tadalafil attenuates mitochondrial dysfunction in type 2 diabetic hearts: potential role of NO/SIRT1/PGC-1alpha signaling. American journal of physiology. Heart and circulatory physiology 306, H1558-1568.

Kukat, C. and Larsson, N.G. (2013). mtDNA makes a U-turn for the mitochondrial nucleoid. Trends in cell biology 23, 457-463.

Kundu, B.K., Zhong, M., Sen, S., Davogustto, G., Keller, S.R. and Taegtmeyer, H. (2015). Remodeling of glucose metabolism precedes pressure overload-induced left ventricular hypertrophy: review of a hypothesis. Cardiology 130, 211-220.

Laganiere, J., Tremblay, G.B., Dufour, C.R., Giroux, S., Rousseau, F. and Giguere, V. (2004). A polymorphic autoregulatory hormone response element in the human estrogen-related receptor alpha (ERRalpha) promoter dictates peroxisome proliferator-activated receptor gamma coactivator-1alpha control of ERRalpha expression. The Journal of biological chemistry 279, 18504-18510.

Lai, L., Leone, T.C., Zechner, C., Schaeffer, P.J., Kelly, S.M., Flanagan, D.P., Medeiros, D.M., Kovacs, A. and Kelly, D.P. (2008). Transcriptional coactivators PGC-1alpha and PGC-lbeta control overlapping programs required for perinatal maturation of the heart. Genes and development 22, 1948-1961.

Lai, L., Wang, M., Martin, O.J., Leone, T.C., Vega, R.B., Han, X. and Kelly, D.P. (2014). A role for peroxisome proliferator-activated receptor gamma coactivator 1 (PGC-1) in the regulation of cardiac mitochondrial phospholipid biosynthesis. The Journal of biological chemistry 289, 2250-2259.

Lehman, J.J., Barger, P.M., Kovacs, A., Saffitz, J.E., Medeiros, D.M. and Kelly, D.P. (2000). Peroxisome proliferator-activated receptor gamma coactivator-1 promotes cardiac mitochondrial biogenesis. The Journal of clinical investigation 106, 847-856.

Lehman, J.J., Boudina, S., Banke, N.H., Sambandam, N., Han, X., Young, D.M., Leone, T.C., Gross, R.W., Lewandowski, E.D., Abel, E.D., et al. (2008). The transcriptional coactivator PGC-1alpha is essential for maximal and efficient cardiac mitochondrial fatty acid oxidation and lipid 
homeostasis. American journal of physiology. Heart and circulatory physiology 295, H185-196.

Lelliott, C.J., Medina-Gomez, G., Petrovic, N., Kis, A., Feldmann, H.M., Bjursell, M., Parker, N., Curtis, K., Campbell, M., Hu, P., et al. (2006). Ablation of PGC-1beta results in defective mitochondrial activity, thermogenesis, hepatic function, and cardiac performance. PLoS biology 4, e369.

Lerin, C., Rodgers, J.T., Kalume, D.E., Kim, S.H., Pandey, A. and Puigserver, P. (2006). GCN5 acetyltransferase complex controls glucose metabolism through transcriptional repression of PGC-1alpha. Cell metabolism 3, 429-438.

Li, X., Monks, B., Ge, Q. and Birnbaum, M.J. (2007). Akt/PKB regulates hepatic metabolism by directly inhibiting PGC-1alpha transcription coactivator. Nature 447, 1012-1016.

Liang, Z., Li, T., Jiang, S., Xu, J., Di, W., Yang, Z., $\mathrm{Hu}, \mathrm{W}$. and Yang, Y. (2017). AMPK: a novel target for treating hepatic fibrosis. Oncotarget 8 , 62780-62792.

Lin, J., Puigserver, P., Donovan, J., Tarr, P. and Spiegelman, B.M. (2002). Peroxisome proliferator-activated receptor gamma coactivator 1beta (PGC-1beta), a novel PGC-1-related transcription coactivator associated with host cell factor. The Journal of biological chemistry 277 , 1645-1648.

Liu, J., Wang, P., Luo, J., Huang, Y., He, L., Yang, H., Li, Q., Wu, S., Zhelyabovska, O. and Yang, Q. (2011). Peroxisome proliferator-activated receptor beta/delta activation in adult hearts facilitates mitochondrial function and cardiac performance under pressure-overload condition. Hypertension 57, 223-230.

Lu, Z., Xu, X., Hu, X., Fassett, J., Zhu, G., Tao, Y., Li, J., Huang, Y., Zhang, P., Zhao, B., et al. (2010). PGC-1 alpha regulates expression of myocardial mitochondrial antioxidants and myocardial oxidative stress after chronic systolic overload. Antioxidants and redox signaling 13, 1011-1022.

Luan, A., Tang, F., Yang, Y., Lu, M., Wang, H. and Zhang, Y. (2015). Astragalus polysaccharide attenuates isoproterenol-induced cardiac hypertrophy by regulating TNF-alpha/PGC-1alpha signaling mediated energy biosynthesis. Environmental toxicology and pharmacology 39, 1081-1090.

Ma, Z., Yang, Y., Di, S., Feng, X., Liu, D., Jiang, S., Hu, W., Qin, Z., Li, Y., Lv, J., et al. (2017). Pterostilbene exerts anticancer activity on nonsmall-cell lung cancer via activating endoplasmic reticulum stress. Scientific reports 7, 8091.
Martin, O.J., Lai, L., Soundarapandian, M.M., Leone, T.C., Zorzano, A., Keller, M.P., Attie, A.D., Muoio, D.M. and Kelly, D.P. (2014). A role for peroxisome proliferator-activated receptor gamma coactivator-1 in the control of mitochondrial dynamics during postnatal cardiac growth. Circulation research 114, 626-636.

McLeod, C.J., Pagel, I. and Sack, M.N. (2005). The mitochondrial biogenesis regulatory program in cardiac adaptation to ischemia--a putative target for therapeutic intervention. Trends in cardiovascular medicine 15, 118-123.

Monsalve, M., Wu, Z., Adelmant, G., Puigserver, P., Fan, M. and Spiegelman, B.M. (2000). Direct coupling of transcription and mRNA processing through the thermogenic coactivator PGC-1. Molecular cell 6, 307-316.

Palomer, X., Salvado, L., Barroso, E. and VazquezCarrera, M. (2013). An overview of the crosstalk between inflammatory processes and metabolic dysregulation during diabetic cardiomyopathy. International journal of cardiology 168 , 3160-3172.

Park, S.Y., Cho, Y.R., Finck, B.N., Kim, H.J., Higashimori, T., Hong, E.G., Lee, M.K., Danton, C., Deshmukh, S., Cline, G.W., et al. (2005). Cardiac-specific overexpression of peroxisome proliferator-activated receptor-alpha causes insulin resistance in heart and liver. Diabetes 54, 2514-2524.

Patten, I.S. and Arany, Z. (2012). PGC-1 coactivators in the cardiovascular system. Trends in endocrinology and metabolism: TEM 23, 90-97.

Ping, Z., Zhang, L.F., Cui, Y.J., Chang, Y.M., Jiang, C.W., Meng, Z.Z., Xu, P., Liu, H.Y., Wang, D.Y. and Cao, X.B. (2015). The Protective Effects of Salidroside from Exhaustive Exercise-Induced Heart Injury by Enhancing the PGC-1 alpha NRF1/NRF2 Pathway and Mitochondrial Respiratory Function in Rats. Oxidative medicine and cellular longevity 2015, 876825.

Pohjoismaki, J.L., Boettger, T., Liu, Z., Goffart, S., Szibor, M. and Braun, T. (2012). Oxidative stress during mitochondrial biogenesis compromises mtDNA integrity in growing hearts and induces a global DNA repair response. Nucleic acids research 40, 6595-6607.

Puigserver, P., Adelmant, G., Wu, Z., Fan, M., Xu, J., O'Malley, B. and Spiegelman, B.M. (1999). Activation of PPARgamma coactivator-1 through transcription factor docking. Science 286, 1368-1371.

Puigserver, P., Wu, Z., Park, C.W., Graves, R., Wright, M. and Spiegelman, B.M. (1998). A cold- 
inducible coactivator of nuclear receptors linked to adaptive thermogenesis. Cell 92, 829-839.

Ramachandran, B., Yu, G. and Gulick, T. (2008). Nuclear respiratory factor 1 controls myocyte enhancer factor $2 \mathrm{~A}$ transcription to provide a mechanism for coordinate expression of respiratory chain subunits. The Journal of biological chemistry 283, 11935-11946.

Ranhotra, H.S. (2010). Long-term caloric restriction up-regulates PPAR gamma co-activator 1 alpha (PGC-1alpha) expression in mice. Indian journal of biochemistry and biophysics 47, 272-277.

Rowe, G.C., Jiang, A. and Arany, Z. (2010). PGC-1 coactivators in cardiac development and disease. Circulation research 107, 825-838.

Russell, L.K., Mansfield, C.M., Lehman, J.J., Kovacs, A., Courtois, M., Saffitz, J.E., Medeiros, D.M., Valencik, M.L., McDonald, J.A. and Kelly, D.P. (2004). Cardiac-specific induction of the transcriptional coactivator peroxisome proliferatoractivated receptor gamma coactivator-1alpha promotes mitochondrial biogenesis and reversible cardiomyopathy in a developmental stagedependent manner. Circulation research 94, 525-533.

Rytinki, M.M. and Palvimo, J.J. (2009). SUMOylation attenuates the function of PGC-1alpha. The Journal of biological chemistry 284, 26184-26193.

Sano, M. and Schneider, M.D. (2004). Cyclindependent kinase-9: an RNAPII kinase at the nexus of cardiac growth and death cascades. Circulation research 95, 867-876.

Scarpulla, R.C. (2011). Metabolic control of mitochondrial biogenesis through the PGC-1 family regulatory network. Biochimica et biophysica acta 1813, 1269-1278.

Schaeffer, P.J., Wende, A.R., Magee, C.J., Neilson, J.R., Leone, T.C., Chen, F. and Kelly, D.P. (2004). Calcineurin and calcium/calmodulin-dependent protein kinase activate distinct metabolic gene regulatory programs in cardiac muscle. The Journal of biological chemistry 279, 39593-39603.

Scharf, M., Neef, S., Freund, R., Geers-Knorr, C., Franz-Wachtel, M., Brandis, A., Krone, D., Schneider, H., Groos, S., Menon, M.B., et al. (2013). Mitogen-activated protein kinase-activated protein kinases 2 and 3 regulate SERCA2a expression and fiber type composition to modulate skeletal muscle and cardiomyocyte function. Molecular and cellular biology 33, 2586-2602.

Schilling, J. and Kelly, D.P. (2011). The PGC-1 cascade as a therapeutic target for heart failure.
Journal of molecular and cellular cardiology 51, 578-583.

Schilling, J., Lai, L., Sambandam, N., Dey, C.E., Leone, T.C. and Kelly, D.P. (2011). Toll-like receptor-mediated inflammatory signaling reprograms cardiac energy metabolism by repressing peroxisome proliferator-activated receptor gamma coactivator-1 signaling. Circulation. Heart failure 4, 474-482.

Schreiber, S.N., Emter, R., Hock, M.B., Knutti, D., Cardenas, J., Podvinec, M., Oakeley, E.J. and Kralli, A. (2004). The estrogen-related receptor alpha (ERRalpha) functions in PPARgamma coactivator 1alpha (PGC-1alpha)-induced mitochondrial biogenesis. Proceedings of the National Academy of Sciences of the United States of America 101, 6472-6477.

Schreiber, S.N., Knutti, D., Brogli, K., Uhlmann, T. and Kralli, A. (2003). The transcriptional coactivator PGC-1 regulates the expression and activity of the orphan nuclear receptor estrogenrelated receptor alpha (ERRalpha). The Journal of biological chemistry 278, 9013-9018.

Sen, S., Kundu, B.K., Wu, H.C., Hashmi, S.S., Guthrie, P., Locke, L.W., Roy, R.J., Matherne, G.P., Berr, S.S., Terwelp, M., et al. (2013). Glucose regulation of load-induced mTOR signaling and ER stress in mammalian heart. Journal of the American Heart Association 2, e004796.

Shen, L., Wang, H. and Ye, P. (2014). [Effects of pioglitazone on myocardial peroxisome proliferator-activated receptor gamma co-activator lalpha expression in rats with myocardial ischemia/reperfusion injury]. Nan fang yi ke da xue xue bao $=$ Journal of Southern Medical University 34, 197-200.

Sonoda, J., Laganiere, J., Mehl, I.R., Barish, G.D., Chong, L.W., Li, X., Scheffler, I.E., Mock, D.C., Bataille, A.R., Robert, F., et al. (2007). Nuclear receptor ERR alpha and coactivator PGC-1 beta are effectors of IFN-gamma-induced host defense. Genes and development 21, 1909-1920.

Sun, C.K., Chang, L.T., Sheu, J.J., Wang, C.Y., Youssef, A.A., Wu, C.J., Chua, S. and Yip, H.K. (2007). Losartan preserves integrity of cardiac gap junctions and PGC-1 alpha gene expression and prevents cellular apoptosis in remote area of left ventricular myocardium following acute myocardial infarction. International heart journal 48, 533-546.

Sun, L., Zang, W.J., Wang, H., Zhao, M., Yu, X.J., $\mathrm{He}, \mathrm{X}$., Miao, Y. and Zhou, J. (2014). Acetylcholine promotes ROS detoxification against hypoxia/ reoxygenation-induced oxidative stress through 
FoxO3a/PGC-1alpha dependent superoxide dismutase. Cellular physiology and biochemistry : international journal of experimental cellular physiology, biochemistry, and pharmacology 34 , 1614-1625.

Taegtmeyer, H., Sen, S. and Vela, D. (2010). Return to the fetal gene program: a suggested metabolic link to gene expression in the heart. Annals of the New York Academy of Sciences 1188, 191-198.

Tao, L., Bei, Y., Lin, S., Zhang, H., Zhou, Y., Jiang, J., Chen, P., Shen, S., Xiao, J. and Li, X. (2015). Exercise Training Protects Against Acute Myocardial Infarction via Improving Myocardial Energy Metabolism and Mitochondrial Biogenesis. Cellular physiology and biochemistry : international journal of experimental cellular physiology, biochemistry, and pharmacology 37 , 162-175.

Teyssier, C., Ma, H., Emter, R., Kralli, A. and Stallcup, M.R. (2005). Activation of nuclear receptor coactivator PGC-1alpha by arginine methylation. Genes and development 19, 1466-1473.

Trausch-Azar, J.S., Abed, M., Orian, A. and Schwartz, A.L. (2015). Isoform-specific SCF(Fbw7) ubiquitination mediates differential regulation of PGC-1alpha. Journal of cellular physiology 230, 842-852.

Tuomainen, T. and Tavi, P. (2017). The role of cardiac energy metabolism in cardiac hypertrophy and failure. Experimental cell research.

Van Berendoncks, A.M., Garnier, A., Beckers, P., Hoymans, V.Y., Possemiers, N., Fortin, D., Van Hoof, V., Dewilde, S., Vrints, C.J., VenturaClapier, R., et al. (2011). Exercise training reverses adiponectin resistance in skeletal muscle of patients with chronic heart failure. Heart 97, 1403-1409.

Vats, D., Mukundan, L., Odegaard, J.I., Zhang, L., Smith, K.L., Morel, C.R., Wagner, R.A., Greaves, D.R., Murray, P.J. and Chawla, A. (2006). Oxidative metabolism and PGC-1beta attenuate macrophage-mediated inflammation. Cell metabolism 4, 13-24.

Venditti, P., Napolitano, G., Barone, D., Pervito, E. and Di Meo, S. (2016). Vitamin E-enriched diet reduces adaptive responses to training determining respiratory capacity and redox homeostasis in rat heart. Free radical research 50, 56-67.

Vercauteren, K., Gleyzer, N. and Scarpulla, R.C. (2009). Short hairpin RNA-mediated silencing of PRC (PGC-1-related coactivator) results in a severe respiratory chain deficiency associated with the proliferation of aberrant mitochondria.
The Journal of biological chemistry 284 , 2307-2319.

Villena, J.A. (2015). New insights into PGC-1 coactivators: redefining their role in the regulation of mitochondrial function and beyond. The FEBS journal 282, 647-672.

Virbasius, C.A., Virbasius, J.V. and Scarpulla, R.C. (1993). NRF-1, an activator involved in nuclearmitochondrial interactions, utilizes a new DNAbinding domain conserved in a family of developmental regulators. Genes and development 7, 2431-2445.

Virbasius, J.V., Virbasius, C.A. and Scarpulla, R.C. (1993). Identity of GABP with NRF-2, a multisubunit activator of cytochrome oxidase expression, reveals a cellular role for an ETS domain activator of viral promoters. Genes and development 7, 380-392.

Wallberg, A.E., Yamamura, S., Malik, S., Spiegelman, B.M. and Roeder, R.G. (2003). Coordination of p300-mediated chromatin remodeling and TRAP/mediator function through coactivator PGC-1alpha. Molecular cell 12, 1137-1149.

Wan, X., Gupta, S., Zago, M.P., Davidson, M.M., Dousset, P., Amoroso, A. and Garg, N.J. (2012). Defects of mtDNA replication impaired mitochondrial biogenesis during Trypanosoma cruzi infection in human cardiomyocytes and chagasic patients: the role of $\mathrm{Nrf} 1 / 2$ and antioxidant response. Journal of the American Heart Association 1, e003855.

Wang, J., Wilhelmsson, H., Graff, C., Li, H., Oldfors, A., Rustin, P., Bruning, J.C., Kahn, C.R., Clayton, D.A., Barsh, G.S., et al. (1999). Dilated cardiomyopathy and atrioventricular conduction blocks induced by heart-specific inactivation of mitochondrial DNA gene expression. Nature genetics 21, 133-137.

Wang, P., Liu, J., Li, Y., Wu, S., Luo, J., Yang, H., Subbiah, R., Chatham, J., Zhelyabovska, O. and Yang, Q. (2010). Peroxisome proliferatoractivated receptor $\{$ delta\} is an essential transcriptional regulator for mitochondrial protection and biogenesis in adult heart. Circulation research 106, 911-919.

Watson, P.A., Reusch, J.E., McCune, S.A., Leinwand, L.A., Luckey, S.W., Konhilas, J.P., Brown, D.A., Chicco, A.J., Sparagna, G.C., Long, C.S., et al. (2007). Restoration of CREB function is linked to completion and stabilization of adaptive cardiac hypertrophy in response to exercise. American journal of physiology. Heart and circulatory physiology 293, H246-259. 
Wei, W., Wang, X., Yang, M., Smith, L.C., Dechow, P.C., Sonoda, J., Evans, R.M. and Wan, Y. (2010). PGC1beta mediates PPARgamma activation of osteoclastogenesis and rosiglitazone-induced bone loss. Cell metabolism 11, 503-516.

Whittington, H.J., Harding, I., Stephenson, C.I., Bell, R., Hausenloy, D.J., Mocanu, M.M. and Yellon, D.M. (2013). Cardioprotection in the aging, diabetic heart: the loss of protective Akt signalling. Cardiovascular research 99, 694-704.

Xin, Z., Ma, Z., Hu, W., Jiang, S., Yang, Z., Li, T., Chen, F., Jia, G. and Yang, Y. (2017). FOXO1/3: Potential suppressors of fibrosis. Ageing research reviews 41, 42-52.

Xu, M.C., Shi, H.M., Gao, X.F. and Wang, H. (2013). Salidroside attenuates myocardial ischemiareperfusion injury via PI3K/Akt signaling pathway. Journal of Asian natural products research 15, 244-252.

Yu, L., Di, W., Dong, X., Li, Z., Xue, X., Zhang, J., Wang, Q., Xiao, X., Han, J., Yang, Y., et al. (2017). Diallyl trisulfide exerts cardioprotection against myocardial ischemia-reperfusion injury in diabetic state, role of AMPK-mediated AKT/ GSK-3beta/HIF-1alpha activation. Oncotarget 8 , 74791-74805.
Yu, L., Li, S., Tang, X., Li, Z., Zhang, J., Xue, X., Han, J., Liu, Y., Zhang, Y., Zhang, Y., et al. (2017). Diallyl trisulfide ameliorates myocardial ischemiareperfusion injury by reducing oxidative stress and endoplasmic reticulum stress-mediated apoptosis in type 1 diabetic rats: role of SIRT1 activation. Apoptosis : an international journal on programmed cell death 22, 942-954.

Zhang, S., Jiang, S., Wang, H., Di, W., Deng, C., Jin, Z., Yi, W., Xiao, X., Nie, Y. and Yang, Y. (2017). SIRT6 protects against hepatic ischemia/ reperfusion injury by inhibiting apoptosis and autophagy related cell death. Free radical biology and medicine.

Zhu, L., Wang, Q., Zhang, L., Fang, Z., Zhao, F., Lv, Z., Gu, Z., Zhang, J., Wang, J., Zen, K., et al. (2010). Hypoxia induces PGC-1alpha expression and mitochondrial biogenesis in the myocardium of TOF patients. Cell research 20, 676-687.

Zhu, Y., Ma, A., Zhang, H. and Li, C. (2013). PPARgamma activation attenuates glycatedserum induced pancreatic beta-cell dysfunction through enhancing $\mathrm{Pdx} 1$ and Mafa protein stability. PloS one 8, e56386. 